\title{
Study of nanostructured NiTi shape memory alloy's structure and functional properties
}

\author{
Afonina V.S. ${ }^{1}$, Gizatullin R.M. ${ }^{2}$, Gunderov D.V. ${ }^{3}$, Kalashnikov V.S. ${ }^{1}$, Koledov V.V. ${ }^{4}$, Shavrov V.G. ${ }^{4}$, Istomin- \\ Kastrovsky V.V. ${ }^{4}$ \\ ${ }^{1}$ Moscow State Technical University n. a. N.E. Bauman, 2-nd Baumanskaya, 5, 105005, Moscow, Russia. \\ 2 "Nano-Dent" Co Ltd, Moscow, Russia \\ ${ }^{3}$ Ufa State Aviation Technology University, Karl Marks st. 12, 450000, Ufa, Russia \\ 4 Kotelnikov' Institute of Radioengineering and Electronic of Russian Academy of Sciences, 125009, \\ Mokhovaya 11-7, Moscow, Russia \\ ${ }^{5}$ Moscow Institute of Steels and Alloys, Leninskiy pr. 4, 119049, Moscow, Russia
}

\begin{abstract}
The present work is aimed to study of nanostructured NiTi shape memory alloy's structure and functional properties depending on the type of thermo mechanical treatment. Structure, recoverable strain and reactive force were compared for coarse grain alloys and nanostructured alloy which was prepared by equal chanal angular pressing. The structure of the nanostructured NiTi was studied by means of TEM. Functional properties were studied by three point bending method in wide temperature range. The processing of the alloy by equal canal angular pressing at $450 \mathrm{C}$ results in formation of the structure with mean grain size about $300 \mathrm{~nm}$. The functional properties of nanostructured and coarse grain alloys were compared in terms of maximal recoverable strain, maximal reactive force, specific energy capacity and functional inflexibility. It was found that nanostructured alloy generates essentially higher maximal recoverable force, has higher specific energy capacity and functional inflexibility than coarse grain one deformed as well (up to 7\%). These advantages are most favourable in the field of applications of the shape memory alloys to surgical or dental implant's design.
\end{abstract}

\section{Introduction}

The materials with record functional and mechanical properties are urgently demanded in many modern fields of medicine and manufactory. The most favourable material for such applications as aviation and space technology, dentistry, surgery, orthodontia etc., is nanostructured NiTi shape memory alloy (SMA). Till present, the most effective method of the regulation and improvement of the functional properties of Ti-Ni SMA was a thermo mechanical treatment creating a well-developed dislocation substructure [1]. Application of the new thermomechanical treatment schemes in particular the severe plastic deformation (SPD) can produce nanostructure in the alloy and thus opens extra possibilities for regulation of the structure-sensitive functional properties of SMAs [2-4].

The most effective variant of SPD technique is the equal-channel angular pressing (ECAP) [2-6]. It is currently used in practice as it gives the possibility to create the nanostructure in bulk samples of the alloy. ECAP is a multipass process which leads to the controllable grain size reduction [7]. The record mechanical and functional properties of nanostructured Ti-Ni SMA had been demonstrated in the previous works [8], but it's still unclear how nanostructure produced by ECAP effects functional properties Ti-Ni SMA in wide range of stresses and deformations.

The goal of the present paper is to compare experimentally the structure and thermomechanical properties in stressed conditions, of nanostructured (NS) by ECAP and coarse grain (CG) samples of Ti-Ni SMA. The structure will be studied by TEM and metallographic optical microscopy. The thermomechanical properties of NS and CG NiTi SMAs will be studied by the three point technique in wide range of bending strains, temperatures and stresses. As a result, the difference between NS and high CG alloys will be given in terms of maximal recoverable strain and maximal reactive force. In order to outline the functional properties of NS Ti-Ni SMA in an integral way we are going to introduce such new characteristic quantities of the material as "specific energy capacity" and "functional inflexibility".

newballer@mail.ru

This is an Open Access article distributed under the terms of the Creative Commons Attribution-Noncommercial License (http://creativecommons.org/licenses/by-nc/3.0/), which permits unrestricted use, distribution, and reproduction in any noncommercial medium, provided the original work is properly cited. 


\section{Materials and experimental techniques}

The NS samples of $\mathrm{Ti}_{49.8} \mathrm{Ni}_{50.2}$ SMA for the experiments have been prepared by ECAP at $450 \mathrm{C}$ by 8 rounds [8]. The study involves the comparative investigation of NS by ECAP and only quenched CG NiTi SMAs from the same ingot. The samples for the experiments were cut in the form of plates $2,5 \times 12 \times 0.45 \mathrm{~mm}$. The other characteristics are presented in Table.

Table. Samples

\begin{tabular}{|l|l|l|l|l|l|l|l|l|l|l|}
\hline Sample & Composition & $\begin{array}{l}\mathrm{As}, \\
\mathrm{C}\end{array}$ & $\begin{array}{l}\mathrm{Af}, \\
\mathrm{C}\end{array}$ & $\begin{array}{l}\mathrm{Ms}, \\
\mathrm{C}\end{array}$ & $\begin{array}{l}\mathrm{Mf}, \\
\mathrm{C}\end{array}$ & $\begin{array}{l}\sigma_{\text {critical }} \\
\mathrm{MPa}\end{array}$ & $\begin{array}{l}\varepsilon_{\text {critical }} \\
\%\end{array}$ & $\begin{array}{l}\sigma_{\mathrm{M},} \\
\mathrm{MP} \\
\mathrm{a}\end{array}$ & $\begin{array}{l}\mathrm{W}_{\max } \\
\mathrm{J} / \mathrm{m}^{3}\end{array}$ & Notes \\
\hline $\mathrm{CG}$ & $\mathrm{Ti}_{49.8} \mathrm{Ni}_{50.2}$ & 30 & 41 & -5 & -12 & $\begin{array}{l}550- \\
590\end{array}$ & 7 & 200 & 3500 & $\begin{array}{l}\text { Ingot } \\
\text { coarse } \\
\text { specimen }\end{array}$ \\
\hline $\mathrm{NS}$ & $\mathrm{Ti}_{49.8} \mathrm{Ni}_{50.2}$ & 12 & 20 & -17 & -32 & 1100 & 7 & 300 & 8000 & $\begin{array}{l}\text { Nanostructured by } \\
\text { grained } \\
\text { ECAP- 8 times at } \\
450 \mathrm{C}\end{array}$ \\
\hline
\end{tabular}

Here: $A_{s}, A_{f}, M_{s}, M_{f}$ - the temperatures of start and finish of the direct and reverse martensite transformation of the unstressed SMA sample, $\sigma_{\text {critical }}$ the stress, when the plastic deformation appears in SMA, $\varepsilon_{\text {critical }}$ - the limit of the recoverable deformations, $\sigma_{\mathrm{M}^{-}}$the stress, when pseudoplasticity, due to stress induced martensitic transition appears at room temperature in SMA sample, $\mathrm{W}_{\max }=\sigma_{\text {critical }} \varepsilon_{\text {critical }}$ - the maximal specific energy capacity of SMA.

The transmission electron microscope JEOL 2001 was used for the investigations of the structure of the samples of Ti-Ni SMA processed by ECAP. The optical microscope with the stage cooled down to liquid nitrogen temperature was used for the surface relief investigations of the SMA samples in the martensitic state. The pre-polishing of the samples have been done well in the austenitic state. The bending deformation versus temperature curves were measured for low stresses $(<35 \mathrm{MPa})$ by the three point method in temperature range $-70 \ldots+70 \mathrm{C}$. The deformations under high stresses (up to $1600 \mathrm{MPa}$ ) also were measured by the three point method at two temperatures: - $120 \mathrm{C}$ (martensitic state) and $+200 \mathrm{C}$ (austenitic state). The experimental set up for three point bending deformations versus temperature measurements included the press with cylindrical form of the surfaces in order to restrict bending strain by the value of $\varepsilon_{0}=10 \%$ for high stresses (up to $1600 \mathrm{MPa}$ ) and $\varepsilon_{0}=1,2 \%$ for low stresses $(<1,2 \%)$ and thus to prevent the destruction of the sample under the loads.

\section{Structure}

\subsection{Structure study by means of TEM}

The results of TEM studies are illustrated in fig. 1. SPD creates nanostructure with 100-500 nm grains in size. The electron diffraction patterns reveal the high mismatch of reflexes between grains. Thus the investigation detectes a large number of grains with a lot of defects, i.e. that nanostructure is in high-stressed condition. The results of TEM investigation of the structure of the Ti-Ni SMA processed by ECAP are in agreement with the results described in [8].

\subsection{Optical observation of surface relief}

The metallographic optical observations presented in fig.2 complement electron microscopy' data. The relief appears on the pre-polished surface of CG samples in martensite phase which is usually attributed to the martensitic twins origin (see fig.2a,b). The characteristic size of the elements of the relief is of the order of 10 $\mu \mathrm{m}$. Unexpectedly, the surface relief of approximately the same characteristic size appears clearly after cooling in martensite state on the surface of NS samples. It was proposed, that appearance of the relief in NS sample can be due to the internal stresses in the alloy. We think that optical study of the surface relief of the pre-polished NS SMA samples in martensite state is useful for the examination of the level of the internal stresses on micrometer scale as well as TEM study can reveal the stress level on nanometer scale of the dimensions of the alloy's structure. The level of internal stresses in turn may affect the NS SMA's quality. 


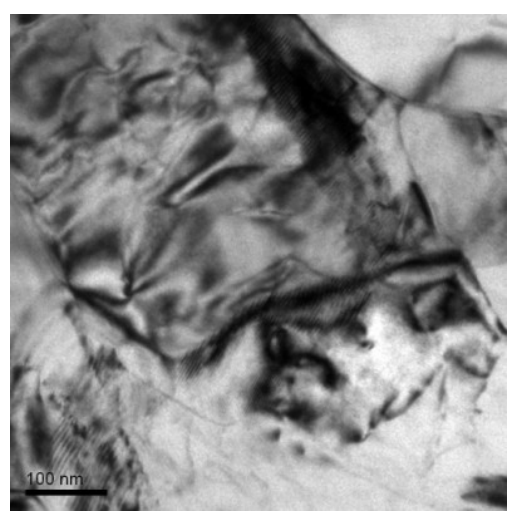

a

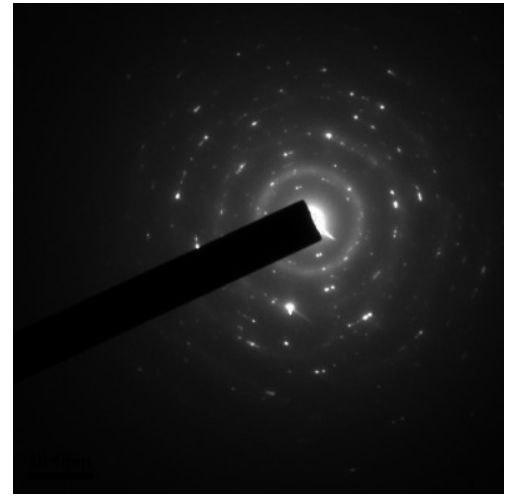

c

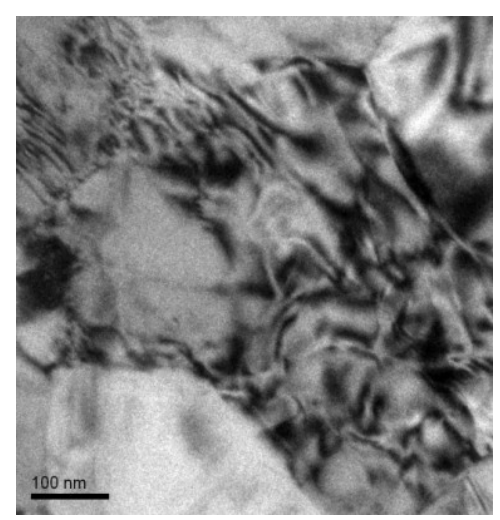

b

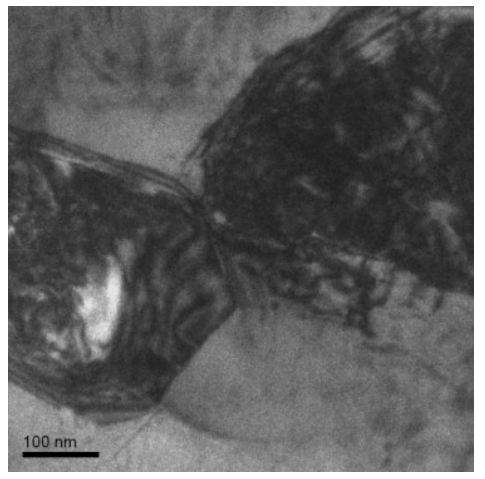

d

Fig 1. TEM study of NS NiTi alloy. Structure of grains (a,b), electron diffraction pattern (c), stressed condition in the grains and grain boundaries (d).

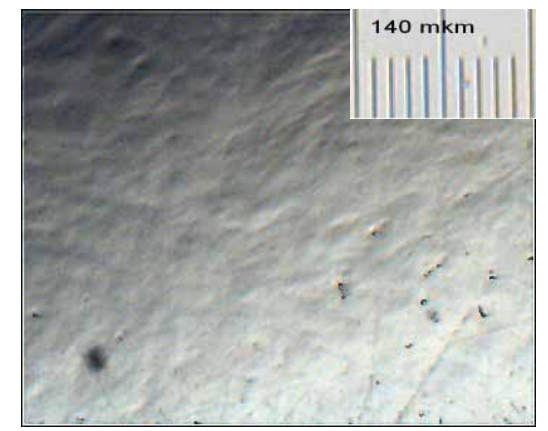

a

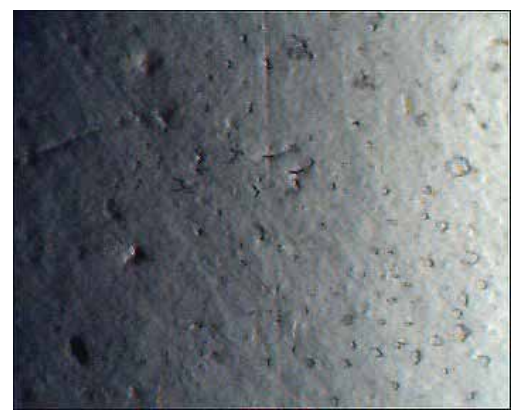

C

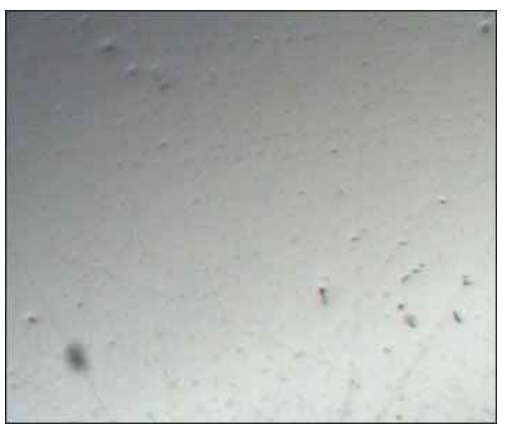

b

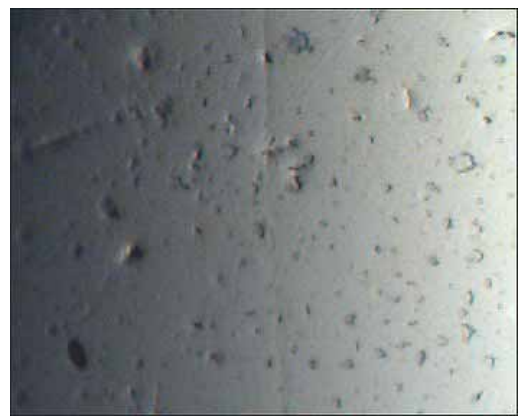

d

Fig 2. Microscopic photos of pre-polished in austenite surface of NS Ni-Ti (a,b) and CG (c,d). (b,d) - austenite, (a,c)martensite. 


\section{Results \\ 4.1 Bending deformation - temperature curves}

The comparative results of the mesurment of stress-temperature curves of CG and NS samples by three point bending method under relatively low stresses $(<35 \mathrm{MPa})$ are presented on Fig.3 a,b. The curves have typical for SMA's hysteretic form. The deformation is restricted by the value of $\varepsilon_{0}=1.2 \%$ which is due to cylindrical form of press. It can be seen that the temperatures of martensite transformation for NS sample lower than for CG one (see Table). The reactive force is higher for NS sample than for CG one at the same given deformation.

It was also noted that during transformation from austenite to martensite R-phase appears but the content of R-phase in NS sample smaller than in CG sample. Furthermore NS sample does not have such strong training ability as demonstrates CG, which can be seen on Fig.3a in circled area. The conclusion is that functional properties of NS Ti-Ni SMA are more stable than that of CG.

\subsection{Bending stress - deformation curves}

The experiments on thermomechanical properties at high stresses (up to $1600 \mathrm{MPa}$ ) have been carried out by the different variant of three point method. In these experiments the bending deformations of NS and CG samples were measured 2 times: after cooling by liquid nitrogen (well in the martensite state) and after heating up to 200 $\mathrm{C}$ (well in austenite state). The samples were bended using different loads. As a result the three quantities: deformation of loaded sample after cooling $\left(\varepsilon_{\mathrm{s}}\right)$, after heating $\left(\varepsilon_{\mathrm{h}}\right)$ and recoverable deformation $\left(\varepsilon_{\mathrm{r}}=\varepsilon_{\mathrm{s}}-\varepsilon_{\mathrm{h}}\right)$, were depicted versus applied strain for CG and NS samples on the graphs fig. 4 a,b.

The $\varepsilon_{\mathrm{s}}$ deformation for both of the samples steadily rises during growth of load, as it can be seen from fig. 4 a,b. It's restricted by the value of $\varepsilon_{0}=10 \%$ which is due to cylindrical form of press. The $\varepsilon_{\mathrm{h}}$ deformation is equal to zero in stress ranges up to $500 \mathrm{MPa}$ for CG sample and $1100 \mathrm{MPa}$ for NS sample. After that the plastic deformation appears and sample cannot fully recover previous shape at heating. The plateau of $\varepsilon_{\mathrm{h}}$ deformation (in stress ranges 650-1100 MPa for CG sample and 1100-1500 MPa for NS sample) can be connected with deformational hardening of the samples.

The cracks formed by the movement of dislocations appear on strained side of the sample after application of bending stress more than $1100 \mathrm{MPa}$ for CG sample and $1500 \mathrm{MPa}$ for NS sample, with the deformation being rather plastic than elastic. The NS sample absolutely recovers given deformation for the stresses up to $1100 \mathrm{MPa}$. The CG sample absolutely recovers given deformation for the stresses up to $500 \mathrm{MPa}$. The recoverable part of the overall deformation at $1600 \mathrm{MPa}$ is $4 \%$ for NS sample and $2.5 \%$ for CG one. The NS sample demonstrates almost 2 times stronger ability to keep functional properties at high stresses.

\subsection{Functional inflexibility and energy capacity}

In order to outline the functional properties of CG and NS SMAs we introduce two new quantities: functional inflexibility and specific energy capacity. Functional inflexibility can be defined as the ratio of stress by relative deformation. This quantity can be used as integral characteristic for spring made of CG or NS NiTi SMA and shows it's inflexibility under heating. As it can be seen from fig. 5 for CG sample the stress-deformation curve in 0-400 MPa stress range grows slower than for NS sample. HG sample can keep functional properties up to 400 $\mathrm{MPa}$ and NS sample can keep functional properties up to $700 \mathrm{MPa}$. NS sample possess of high reactive stress when the given deformation is the same for both of the samples. The maximal functional inflexibility for NS sample is $15.7 \mathrm{GPa}$ and for CG sample is $7.2 \mathrm{GPa}$.

The specific energy capacity can be defined as product of relative deformation and pressure and shows the energy accumulated by alloy due to shape memory effect. As it can be seen from fig.6 CG sample can keep given energy up to $500 \mathrm{MPa}$ and it's energy capacity is equal to about $3500 \mathrm{~J} / \mathrm{m}^{3}$ but NS sample can keep energy up to $1100 \mathrm{MPa}$ and energy capacity is about $8000 \mathrm{~J} / \mathrm{m}^{3}$.

\section{Discussion}

To explain the experimental data the following qualitative model can be proposed. It is based on the suggestion that after nanocristallization the summary area of grain boundaries became higher and every boundary plays role of reinforcing rib. When alloy possesses of high number of such ribs it enhances the integral inflexibility and produce higher reactive force at low deformations during martesitic transition under the load. It's well known that nanostructure produced by SPD in NiTi SMAs improves functional properties because it prevents dislocations movement on high stresses level [9]. In the present paper we note that the nanostructure enhances functional inflexibility because the nanograines' boundaries play the role of reinforcement ribs even on small stresses level. 

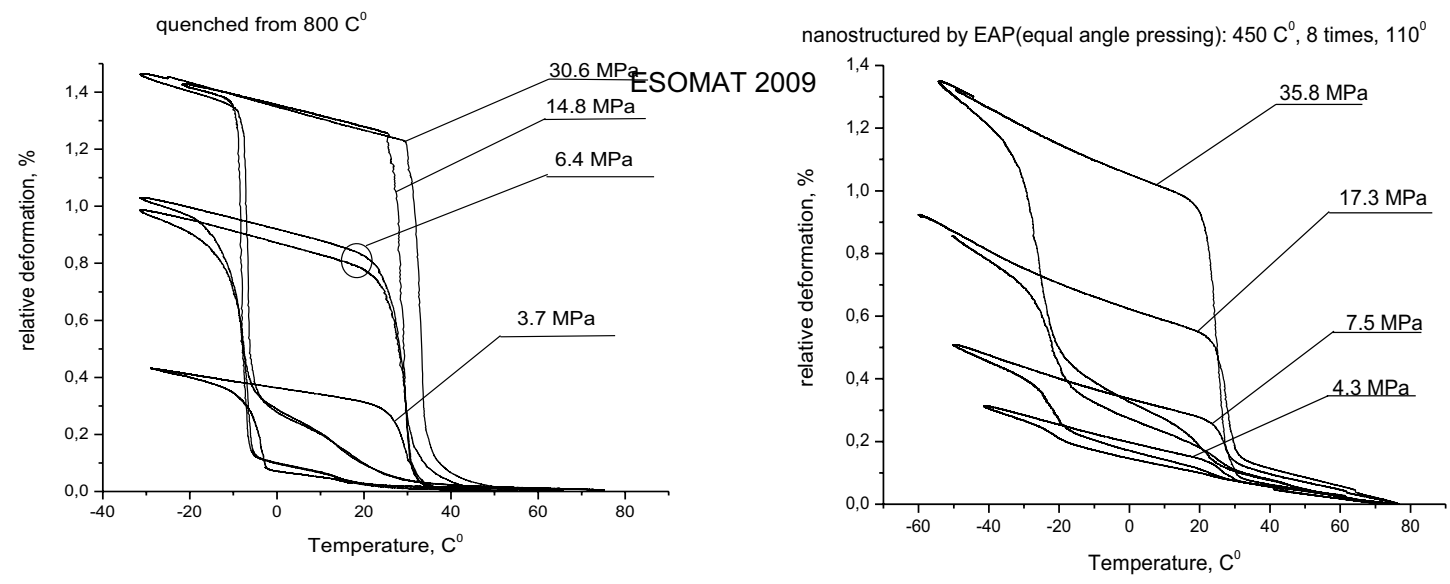

a

b

Fig 3. Relationship between bending deformation, temperature and pressure of CG NiTi alloy (a) and NS by ECAP (b)

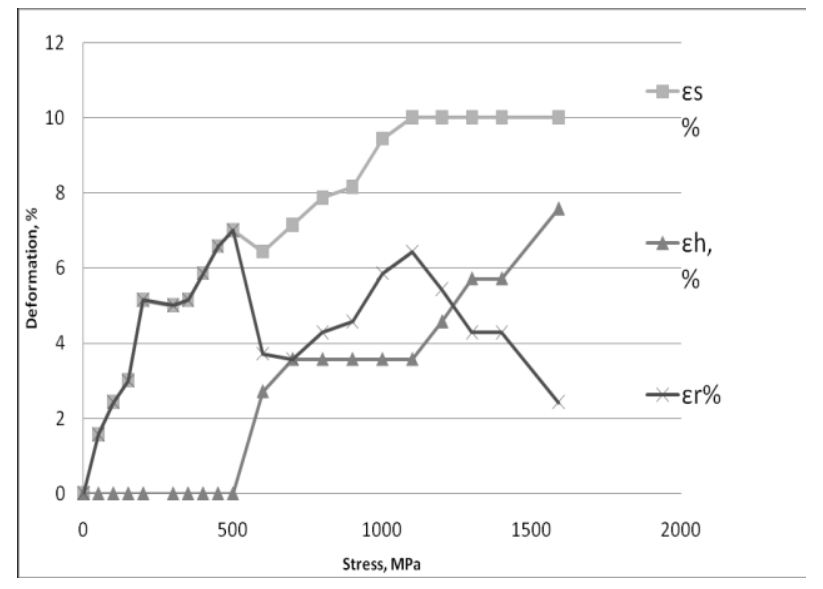

a

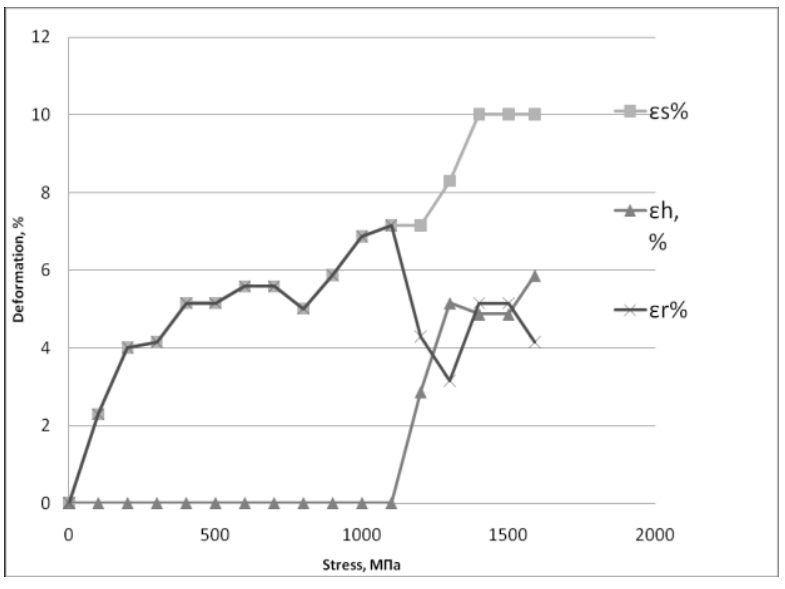

$\mathrm{b}$

Fig 4. Relationship between bending deformation and stress for CG NiTi alloy (a) and NS by ECAP (b)
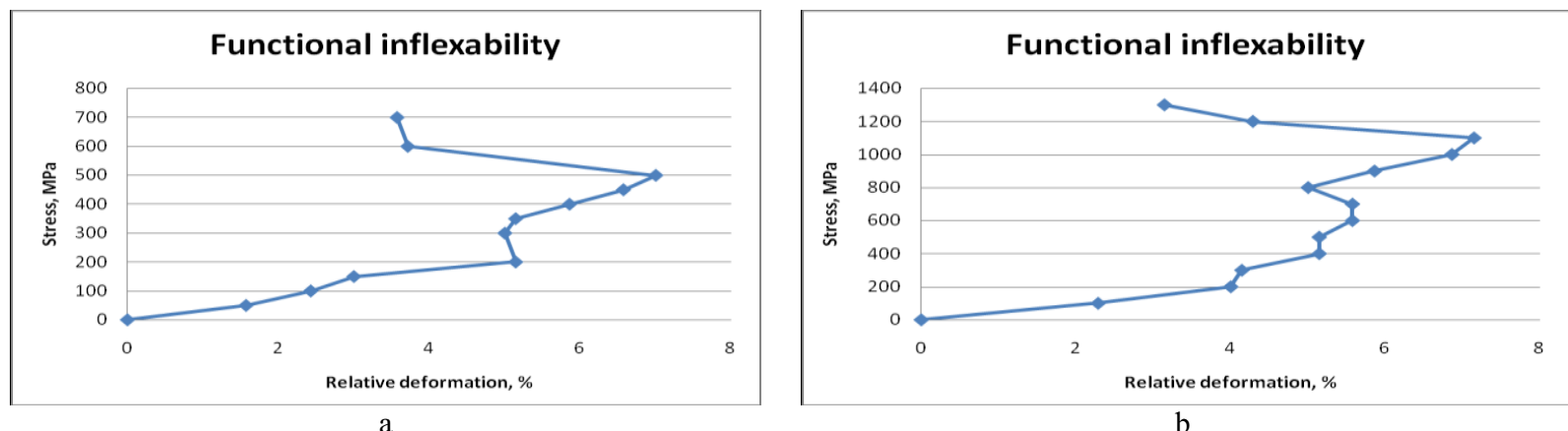

Fig 5. Inflexibility curves show relationship between bending deformation and bending stress for CG NiTi SMA (a) and NS alloys (b).

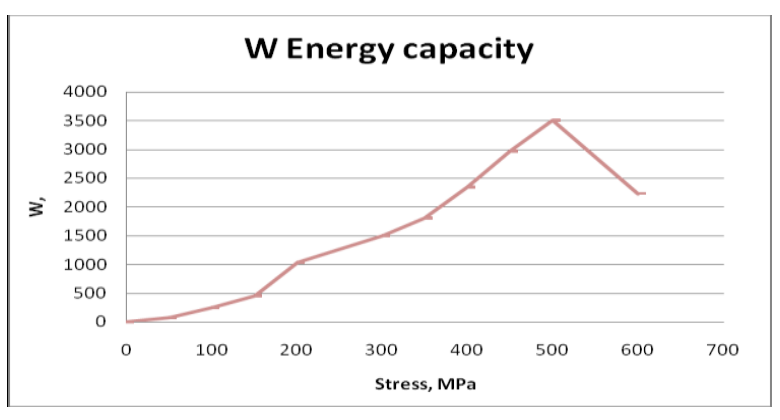

a

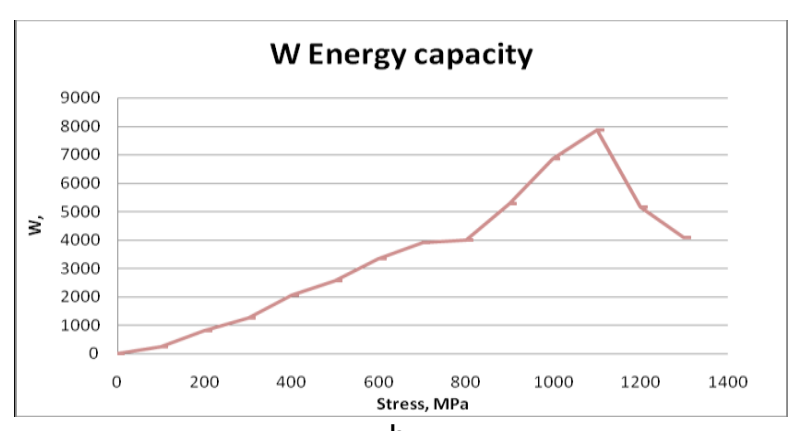

b

Fig 6. Relationship between energy capacity and bending stress of CG (a) and NS NiTi alloys (b). 
We introduce the term "specific energy capacity" to outline functional properties of NS alloy in integral way. Energy capacity consists of two components. First one is high strength: the smaller grain the shorter way dislocation can pass and it leads to strengthening. Second one is outstanding inflexibility: lots of small grains lead to rising of the area of boundaries and enlargement of the number of boundaries and every boundary plays role of reinforcing rib. The energy capacity can be the function of summary area of grain boundaries and their size. Limit of energy capacity for CG sample lower in about 2 times (see Fig. 6.), than for NS sample which has high summary area of grain boundaries than CG sample. We can mention that the most qualitative alloyed spring steels has specific energy capacity not more than $800 \mathrm{~J} / \mathrm{m}^{3}$, while NS NiTi alloy has specific energy capacity about 10 times higher. This gives the opportunities to produce a new class of modern elastic devices for medicine and engineering industry. NS NiTi SMAs are the most favourable for applications in implant design for surgery and dentistry.

The authors are grateful to prof. V.G. Pushin (IPM UD RAS, Ekaterinburg, Russia) and prof S.D. Prokoshkin (MISA, Moscow, Russia) for fruitful discussions. The work was supported by RFBR grant No 09-08-01177 and RAS research program No 27.

\section{References}

[1] V. Brailovski, in: S. Prokoshkin. P. Terriaull. F. Trochu (Eds.). Shape Memory Alloys: Fundamentals. Modeling and Applications. ETS Publ., Montreal. 2003.

[2] R.Z. Valiev. I.V. Aleksandrov. Nanostructural Materials Obtained Using Severe Plastic Deformation. Moscow. 2000.

[3] R.Z. Valiev (Ed.). Proceedings of the International Conference on Nanoma-terials by Severe Plastic Deformation-NANO SPD2. Vienna. December 9-13. 2002. Wiley-VHC Verlag. Weinheim. Germany. 2004. p. 109.

[4] S.D.Prokoshkin, I.Yu. Khmelevskaya, S.V. Dobatkin, I.B. Trubitsyna, E.V. Tatyanin S. Turenne, V. Brailovski, V.V. Stolyarov, E.A. Prokofiev Thermomechanical Conditions For Ultrafine Grained Materials IV. Edited by Y.T. Zhu et al . TMS, 2006

[5] K. Nelsi. Z. Horita. T.G. Langdon. Proceedings of the International Conference on Nanomaterials by Severe Plastic Deformation-NANO SPD2. December 9-13,2002. Wiley-VHC Verlag. Weinheim. Germany. 2004. pp. 746-751.

[6] A. Vinogradov. S. Hashimoto. Proceedings of the International Conference on Nanomaterials by Severe Plastic Deformation-NANO SPD2. December 9-13, 2002. Wiley-VHC Verlag. Weinheim. Germany. 2004. pp. 663-676.

[7] S.D. Prokoshkin. I.Yu. Khmelevskaya. S.V. Dobatkin. I.B. Trubitsyna. E.V. Tatyanin. V.V. Stolyarov. E.A. Prokofiev, Acta Mater. 53 (2005) 2703-2714.

[8] Khmelevskaya, I.Yu., Prokoshkin, S.D., Trubitsyna, I.B., Belousov, M.N., Dobatkin, S.V., Tatyanin, E.V., Korotitskiy, A.V. Structure and properties of Ti-Ni-based alloys after equal-channel angular pressing and highpressure torsion. Materials Science and Engineering., v. A 481-482 (1-2 C) (2008) pp. 119-122.

[9] Prokoshkin, S.D., Brailovskii, V., Khmelevskaya, I.Yu., Dobatkin, S.V., Inaekyan, K.E., Turilina, V.Yu., Demers, V., Tat'yanin, E.V. Creation of substructure and nanostructure in thermomechanical treatment and control of functional properties of Ti - Ni alloys with shape memory effect. Metal Science and Heat Treatment., 47 (2005) pp. 182-187 